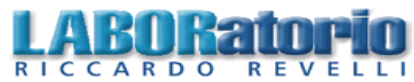

LABORatorio R. Revelli Centre for Employment Studies

Working Paper no. 39

\title{
Would declining exit rates from welfare provide evidence of welfare dependence in homogeneous environments?
}

\author{
Dalit Contini \\ Dipartimento di Statistica e Matematica Applicata alle Scienze Umane, \\ Università di Torino \\ Nicola Negri \\ Dipartimento di Scienza Sociali, Università d Torino
}

September 2006 


\title{
Would declining exit rates from welfare provide evidence of welfare dependence in homogeneous environments?
}

\author{
Dalit Contini and Nicola Negri
}

Negative duration dependence in the exit rate from social assistance is an important issue addressed in the dynamic welfare participation literature. If heterogeneity is properly modelled, the decline of the exit rate is ascribed to a progressive reduction of the capability to get off welfare due to the detrimental effects of the benefit as time in welfare increases (Blank, 1989; Sandefur and Cook, 1998; Dahl and Lorenzen; 2003; Gangl, 2003, Chay et al, 2005). The aim of this paper is to show that the potential corruptive effects of benefits are not easily identified with this analytical strategy. As a starting point we develop a model, coherent with the Bane and Ellwood (1994) theoretical framework, that describes the causal links occurring between work/unemployment, poverty and social assistance. A simulation study is carried out in order to show that negative duration dependence in the exit rate from welfare may arise in environments where no corruptive effects of benefits are at work, even in the absence of heterogeneity at the onset of the process. Thus, negative duration dependence in the exit rate from welfare does not imply 'welfare dependence': the observed pattern may be due to effects of persistence in poverty or in unemployment.

\section{Introduction}

The duration of economic subsidies paid out by public assistance is an important characteristic distinguishing different local welfare systems (Saraceno, 2002). The idea is that systems characterised by long welfare spells are not effective, costly and therefore inefficient. Moreover, according to the 'welfare trap' theory, long spells may itself constitute a cause of poverty, as recipients may develop dependence on the subsidy reducing the chances of becoming 
autonomous from public support. In this perspective, systems providing long-term benefits are judged negatively not only because they are considered less efficient in solving beneficiaries' problems, but also because this inefficiency exacerbates their situation.

The exit rate from welfare is thus a widespread subject of analysis in the welfare dynamic participation literature. The underlying assumption is that if subsidies have a corrupting effect, individual exit probabilities should diminish as time in assistance increases. In the following sections we argue, instead, that negative duration dependence in the exit rate from welfare is not necessarily a consequence of welfare dependence, even in the absence of unobserved heterogeneity ${ }^{1}$.

As a starting point, we develop a model that illustrates the possible causal links occurring between the domains of work/unemployment, poverty and social assistance. The model is coherent with the framework developed by Bane and Ellwood (1994), according to which selfsufficiency from public support may be difficult to reach as a consequence of different behavioural models, emphasizing respectively: choices and incentives, confidence and control, values and culture. Our model 'dissects' (Hedström, 2005) the effects between unemployment, poverty and social assistance with respect to individual opportunities, preferences, and expectations. We claim that the behavioural mechanisms of Bane and Ellwood are potentially activated by all the domains under study: a welfare recipient could have a hard time becoming autonomous not because he receives the benefit, but simply because he is poor or unemployed. Thus, the model is useful for distinguishing the effects of benefit receipt from other factors which are not related to the welfare program.

The paper is organized as follows. In the following section we briefly review the empirical literature on welfare dependence and deal with the issue of negative duration dependence in the exit rate from welfare. We discuss the arguments provided in the literature to explain negative duration dependence, highlighting some inconsistencies in this line of reasoning. The qualitative model linking work/unemployment, poverty and social assistance is then developed. A 
simulation exercise based on a simplified version of the previous model is carried out with the aim of showing that negative duration dependence in the exit rate from welfare may be observed in environments where no corruptive effects of benefits are at work. Conclusions follow.

\section{Welfare dependence in the literature}

The most common definition of welfare dependence focuses on the length of individual welfare

spells, with longer episodes taken as representing greater dependence (Gottschalk, Moffit; 1994)². Although the concept of welfare dependence is generally related to the amount of time spent on welfare, the causal effect of the subsidy is frequently referred to. The idea is that a prolonged period on welfare may be the result of the detrimental effect of the benefit itself on recipients' choices and behaviour.

One major strand of the literature has focused on evaluating the work disincentives of income support programs, i.e. the negative effects of welfare transfers on labor supply (Dazinger et al, 1981; Ermish and Wright, 1990; Hoynes, 1996; see also Moffit, 1992, Moffit, 2002 and Blank, 2002 for extensive surveys). Reference is to classic economic theory according to which individuals - subject to the constraints given by actual work opportunities and welfare policies choose whether to work and how much to work following the principle of utility maximization. Most of the empirical studies, largely referred to the U.S. program $A F D C^{3}$, exploit time and cross-state variation in the benefit level ${ }^{4}$ for identification of the impact of the programs. The focus is on assessing the absolute magnitude of the labor supply reduction due to benefit receipt by comparing labor market behaviour at different benefit levels (Moffit, 2002). This body of work as a whole confirms that transfer programs considerably reduce work effort. Recent studies deal with the incentive effect of welfare reforms, the role of work requirements, sanctions, time limits, education or training programs (for example: Moffit, 2003; Van den Berg et al; 2004).

Another strand of the literature is that of welfare participation. The effects of specific features of policies, such as the level of benefits on welfare participation at a point in time (for 
static models) and on entry/exit rates from welfare (for dynamic models), are estimated As regards exit rates in particular, the aim is to assess the indirect effect of the benefit level on welfare spell length - if people reduce work effort because of the subsidy, time in welfare should increase (Blank, 1989; Hoynes and MaCurdy, 1994, Fortin et al, 2004). Across the studies there is empirical evidence that as the amount of the subsidy increases, participation and entry rates also increase, while exit rates drop.

A number of dynamic participation studies (O’Neill et al, 1987; Blank, 1989; Sandefur and Cook; 1998; Walker and Shaw, 1998; Gustaffson and Voges; 1998; Gustaffson et al, 2002; Dahl and Lorentzen, 2003; Gangl, 2003; Chay et al, 2005) address the issue of negative duration dependence in the exit rate from welfare. Some authors define the concept of welfare dependence in this sense (Blank, 1989; Walker and Shaw, 1998; Sandefur and Cook, 1998). The term 'negative duration dependence' means that the longer the time spent in welfare, the more difficult it is to exit. The decline of the exit rate is related to the reduction of the capability to get off welfare - due to the detrimental effect of the benefit - as time in welfare passes. Thus, the focus of the statistical analyses is the shape of the hazard function of time on welfare ${ }^{5}$, or, with a similar perspective, of the transition intensity from welfare to a stable working position (Dahl and Lorentzen, 2003; Gangl, 2003) ${ }^{6}$.

But identification of the shape of individuals' hazard and transition functions is not a simple task (Lancaster, 1990). An empirical decreasing exit rate may be due to 'state dependence' (the causal effect of time already spent in welfare) or it may be a spurious effect, due to unobserved heterogeneity ${ }^{7}$. This problem is clearly acknowledged in the empirical welfare evaluation literature. For example, Dahl and Lorentzen (2003, 519) argue that: "The heterogeneity hypothesis claims that beneficiaries with less resources and more problems tend to stay on assistance, while those who are better off tend to leave after a short while. The time dependency hypothesis maintains that time on social assistance influences beneficiaries' attitudes and behaviours in detrimental ways. As time passes claimants lose self-efficacy, morale, motivation or 
skills". In this light, the aim of the empirical work is to consistently estimate the shape of the exit rate, having controlled for all potential sources of heterogeneity - individual differences and features of the context - which could obscure the 'true' causal relation between time spent in welfare and the exit probability from welfare ${ }^{8}$.

The purpose of this paper is to show that estimation of the causal effect of time in welfare over the probability of exiting welfare cannot be successfully accomplished through analysis of the shape of the hazard function - even by controlling for individual differences - because other identification issues arise if the complex nature of the process governing welfare dynamics is not properly taken into account.

\section{Effects of time on welfare and negative duration dependence}

The behavioural explanation provided for negative duration dependence in the exit rate from welfare is that: "[...] people's attitudes and behaviour change over time in response to living on benefit and this, in turn, makes it increasingly difficult for them to leave. [...] claimants may no longer bother to look for work, or may have lost the habit of work that appeals to prospective employers" (Leisering and Leibfried, 1998).

In their influential paper on welfare dependence, Bane and Ellwood (1994) state: "The term dependency is used quite loosely in public discussion and most academic work [...]. Both the popular and the academic treatments of dependency have, in general, been flawed by incomplete, inconsistent, or non-existent behavioural models." Reviewing the literature, they provide a theoretical framework highlighting the reasons for possible detrimental role of time in assistance. They propose three models: the rational choice model, the expectancy model and the cultural model.

The rational choice paradigm motivates most of the empirical studies on work disincentives. Individuals evaluate the available options and select the option with the highest utility: thus, longterm welfare use is the result of a series of reasoned choices. The expectancy model is related to individuals' sense of self-esteem. Dependency may result when people lose a sense of control 
over their lives, ceasing to believe that they can make it without welfare. The cultural model, strictly related to the 'culture of poverty' theory, claims that living in environments where most of the people rely on welfare instead of work may favour the change of attitudes and mores, and the development of a different system of values. According to Bane and Ellwood, it is the expectancy model in particular that assumes that the longer the time on welfare the harder it is to get off, because confidence and self-esteem are expected to decay with time in the system. The cultural model - maintaining the role of the living environment - also suggests that actions may be subject to change with time spent on welfare. On the other hand, the difficulty of leaving welfare ought not to vary with time on the program under the rational choice model.

But what are the mechanisms triggering these effects on recipients' behaviour?

Let us go back to the viewpoint of Dahl and Lorentzen (2003). They maintain that time on welfare causes loss of skills. In a similar fashion, Sandefur and Cook $(1998,764)$ argue that: "To understand whether welfare may be a trap, it is important $[\ldots]$ to look more carefully at why some recipients use welfare for long periods of time. [...] The reasons for this may be that (1) a woman's skills deteriorate [...], (2) the stigma [...] grows stronger [...], (3) the intensity of searching of jobs $[\ldots]$ decreases over the duration of welfare receipt $[\ldots]$ ". Again, reference is to deterioration of skills as one of the intervening effects in the causal relation (welfare as a trap) between income support policy and the capability of going back to work. In his influential review of the literature on evaluation of welfare programs in the USA, Moffit $(1992,26)$ argues that: "Such dependence [negative duration dependence] could arise from the deleterious effects of $A D F C$ receipt itself, as might happen if buman capital deteriorates from lack of se as the spell progresses $[\ldots]$. Yet another explanation $[\ldots]$ is a spurious statistical result arising from the existence of unobserved heterogeneity"'. In this case the causal relation between benefit receipt and exit from welfare (deleterious effects of $A F D C$ ) is assumed to take place because of the intervening effect of human capital deterioration.

We do not find these arguments completely persuasive: 
(i) Skill loss and human capital deterioration occur as a consequence of being out of the labour market, and not directly because of the welfare benefit: unemployed people who are not eligible for income support are also exposed to these risks. If a causal link between welfare participation and unemployment does exist, this link should be more clearly specified.

(ii) Stigma may arise as a consequence of living on public support, but also whenever a person's standard of living is too far below that of the majority of the people around him, i.e. because of poverty.

(iii) Job search reduction may indeed take place because people develop an opportunistic attitude towards the subsidy, but also because of loss of self-confidence, which may result as a response to being out of the labour market or in a condition of economic deprivation. Is job search reduction then ultimately due to welfare, or is it due to unemployment or poverty themselves?

If it is true that in most cases being in welfare implies being poor- most income support policies do not take people out of poverty - and that it may also denote being unemployed (although the link may be weaker), then we should agree that observed persistence in welfare could be the consequence of persistence in poverty or in unemployment. The distinction is crucial if the aim of the empirical research is to evaluate the negative causal effects of income support policies. There seems to be a need for a more precise causal model - linking unemployment, poverty and social assistance receipt - to disentangle these effects. A qualitative version of such a model is developed in the next section.

We may add that, aside from identification issues, the analysis of the shape of the exit rate from welfare could be a relevant topic of investigation only if the interventions are 'according to need' (Saraceno, 2002), so that beneficiaries receive help as long as the need persists (this is the case of northern European welfare systems, of France and Germany, but also of the very strongly category-based $A F D C$ program $^{10}$ in force in the USA until 1996). Instead, in regimes subject to 
budget constraints, a household may find its subsidy revoked even if its economic situation has not improved. Thus, welfare spell length is a relevant outcome for evaluating dependence if it is affected exclusively by beneficiaries' behaviour. What would otherwise be the semantic value of a prolonging of assistance episodes? Who are the agents involved: welfare recipients, who are less willing to find a job, or social workers, who can intervene in a discretionary way to regulate resource allocation?

\section{Linking unemployment, poverty and social assistance}

In Figure 1, $\mathrm{U}$ indicates the area of unemployment while $\mathrm{S}$ indicates 'protected unemployment', that is periods in which a worker receives non-means-tested benefits which are guaranteed by contract in case of job loss. P represents poverty; A represents public social assistance, that is the period during which an individual receives means-tested income support financed by the state and granted to poor households. The arrows indicate the effects (positive or negative) that each area potentially exercises on the others or on itself. We say 'potentially' because some of the effects are not obvious, and their being or not being at work is often an issue of empirical research. The model may not illustrate all the possible interdependencies among unemployment, poverty and assistance, but only those analytically relevant to the present discussion. Thus, it has a merely heuristic value.

(Figure 1 here)

\section{Loss of income due to unemployment (arrow a)}

Not receiving a salary the individual and his family may slide into a condition of poverty. Timing and intensity of the fall into poverty depend on household's characteristics: presence of other working members, availability of savings, solidarity of relatives. The presence of non-means- 
tested unemployment benefits guaranteed for certain categories of workers is also relevant. Relations $e, f, f$ 'intervene here: we will return to them later.

\section{Access to social assistance benefits (arrow $b)$}

Household poverty is a condition for access to means-tested assistance. The relation is not deterministic: there can be situations of assistance without poverty and poverty without assistance. The latter may be due to eligibility rules or to take-up behaviour among the eligible. Institutional factors affect both aspects.

Eligibility rules. The level of poverty giving entitlement to benefits varies across public assistance regimes and often lies below the national poverty threshold. Moreover, welfare regimes can have a universalistic or a category-based orientation (Saraceno, 2002). In the latter case there can be discrimination between 'deserving' and 'non-deserving' poor, and social services may require economic need to be qualified by circumstances such as incapacity to work, presence of small children, etc.. Time limits also affect entitlement to benefits: under some regimes income support can be interrupted even when poverty persists.

Take-up rate. Propensity to turn to social services may be related to obligations and sanctions that may be imposed on welfare recipients. Psychological factors may also intervene alongside with institutional factors: stigma may cause a sense of shame, preventing individuals from claiming public assistance; the so-called 'institutional anorexia' may hinder poor people from obtaining information about their personal rights, or exploiting them fully.

Access to social assistance is also affected by the existence of informal rules working at the local level, thus by how policies are actually implemented.

\section{Unemployment persistency (arrow c)}

With prolonged time in unemployment, the individual slips backwards in the queue of 'employability' making reinsertion in the labour market more difficult ${ }^{11}$. Various mechanisms can 
generate this effect. As elapsed time in unemployment grows longer, skills become obsolete; social contacts facilitating the match between labor supply and demand loosen (Granovetter, 1995); potential employers become mistrustful. Persistence in unemployment may also be due to psychological factors: unemployment can demoralize and 'discourage' the jobless individual to the point where he simply stops looking for work.

\section{Income effect of welfare benefits (arrows b'+a')}

The probability of leaving unemployment is affected by current and expected income (arrow $a^{\prime}$ ). Arrow $b$ ' stands for the income gain provided by social assistance (subsidies may not eliminate poverty, but at least reduce its intensity). The income effect of social assistance on unemployment is represented by the combined effect of $b^{\prime}+a^{\prime}$. As maintained by classical economic theory, benefit provision increases reservation wage and reduces hours of work: the larger the subsidy and the longer its expected duration, the less individuals are attracted by work. Note that the work disincentive may be partially outweighed by substitution effects when the benefit-reduction rate, a tax on earnings while on welfare, is lowered ${ }^{12}$.

From the opposite perspective, being in poverty may instead reinforce unemployment. First, poverty may compromise the capacity to sustain job-search costs (information, communication, transportation, substituting time dedicated to domestic care). Second, in the long run poverty may oblige individuals to accept any kind of job, even precarious, unskilled, physically exhausting and harmful to health, thus increasing marginalization from the labor market. In this light, social assistance benefits may enable interruption of the vicious circle of poverty and unemployment.

\section{Psycho-social effects of welfare benefits (arrow d)}

The relation represents the potential corruptive $^{13}$ effect of time on welfare related to psychological and cultural factors (Bane and Ellwood, 1994). Living on public support, which in certain cultural contexts is equated with living on charity, exposes the individual to social 
disqualification and stigma, imprisoning him in marginal social networks and isolating him even more than unemployment - from those social contacts which help to gain access to work opportunities. -Demoralization and learned helplessness may also take root, favouring the reduction of the intensity of job-search. Moreover, when individuals live in situations of socioeconomic exclusion and spatial segregation, they may progressively internalize behavioural models typical of the so-called 'poverty culture', according to which poor people learn to manage without a regular job. Values and attitudes are affected if the majority of the neighbours relies on welfare rather than work. Thus, preferences may change, making work less attractive.

In neo-classical economics individuals' preferences are taken as given, and the budget line describing available options is only subject to exogenous changes. Both these assumptions must be relaxed if we wish to acknowledge for psycho-social factors ${ }^{14}$.

\section{Psycho-social effects of poverty (arrow a")}

Prolonged time in poverty induces very similar mechanisms - related to stigma, loosening of social networks, loss of confidence, changes of values - to those described for time elapsed on welfare, but have different policy implications. For this reason, it is important to keep them well distinct. We will return to this point.

\section{Effects related to unemployment benefits (arrows e, $f$ and $f^{\prime}$ )}

Workers who lose their job may be entitled to non-means-tested income support guaranteed for certain categories of unemployed (arrow $f$ ), which can prevent or slow the fall into poverty (arrow e). Unemployment benefits may provide a work disincentive similar to that of social assistance, although the effect is likely to be stronger, as the subsidy is more generous in this case. On the other hand, benefits can sustain job-search costs and human capital investments. Like social assistance, unemployment benefits can have demoralizing effects (arrow $f^{\prime}$ ). However, since these benefits are often seen more as a right, they are generally not particularly stigmatizing. 


\section{Policy implications}

The assessment of institutional effects has relevant policy implications. Work disincentives, related to the income effect of the benefit, have been extensively studied. Nowadays, the major concern is to 'make people work', by increasing tax reduction rates, introducing obligations, sanctions, time limits.

On the other hand, psycho-social effects of welfare benefits, as we will see in the following section, are difficult to evaluate. The reason is that many of the factors leading to a reduction in the chances to leave unemployment (stigma, changes of values, loss of confidence) may be ascribed to different domains of the model. The effects related to loss of self-confidence, for example, can occur because of unemployment (arrow c), or because of income deprivation (arrow $\left.a^{\prime}\right)$, or as a consequence of living on public support (arrow d). In all of these cases, difficult to be considered as clearly distinct, loss of confidence leads to a reduction in the chances to leave unemployment. But policy implications are different. If this effect is due to poverty - i.e. not being able to reach the standard of living of the majority - the benefit, providing more income, should have empowerment effects, encouraging self-sufficiency. On the other hand, if the effect is due to living on welfare - i.e. not being able to make it on your own - receiving income support will reduce the chances to find a job: active labor market programs should be endorsed in this case, as the way in which supplementary income is provided is critical for the success of the policy.

\section{Simulation exercise}

We carry out a simulation experiment aimed at showing that negative duration dependence in the exit rate from welfare does not imply the existence of a causal effect of the benefit on working life courses, even in the absence of unobserved heterogeneity. The idea is that negative duration dependence in the exit rate from welfare could instead be due to persistence in poverty 
or in unemployment. Welfare spells are generated under the assumption that no corruptive effects of social assistance are at work: it will be shown that negative duration dependence in the exit rate from welfare may turn up also in this context.

Let's make a very extreme assumption: that social assistance, instead of providing real money, assigns people pieces of paper with no legal value. Moreover, let this 'social assistance' be granted to the same people and with the same rules applying as for real welfare benefits. Obviously, in this environment individual behaviour cannot be affected by the cash transfer. In particular, with reference to the model in fig. 1:

(a) There are no income effects (no b' arrow), implying that social assistance does not provide work disincentives .

(b) Time on welfare does not have any effect on self-confidence or attitudes (no $d$ arrow). Moreover we will ignore unemployment benefits in order to simplify the exposition.

(Figure 2 here)

Let current working condition - and possibly also past unemployment history - affect current poverty status, and let past poverty history and past unemployment history affect the current working condition:

$$
\begin{array}{ll}
U_{t}=f\left(U_{\text {past }}, P_{\text {past }}\right) & \text { through } c, a^{\prime} \text { and } a^{\prime} \\
P_{t}=f\left(U_{t}, U_{\text {past }}\right) & \text { through } a
\end{array}
$$

Given the recursive structure of (1a) and (1b), by repeated substitution of $U_{\text {past }}$ and $P_{\text {past }}$ in equation (1a) we obtain the following:

$$
P_{t}=f\left(P_{\text {past }}\right)
$$

representing the net effect of relations $a, a, a$ "' and $c$. In addition: 


$$
A_{t}=f\left(P_{t}, P_{\text {past }}\right) \quad \text { through } b
$$

The starting point of the simulation study is the reduced form version of the behavioural model depicted in fig. 2, given by (2) and (3). This specification, being still adequate for the present purpose, allows a simple simulation design.

We take a set of identical individuals, all of whom are poor at time $t=1$ (so that there is no heterogeneity at the onset of the process). We impose that they all follow the same process probability rules. We let past poverty experience positively affect the probability of current poverty, thus assuming the existence of a vicious circle of poverty. Let's discuss this condition.

Equation (2) represents a net effect of different relations: arrow $c$, representing persistence in unemployment, implies a positive effect (unemployment as a cause of future unemployment); arrow $a$, income loss due to unemployment, is also a positive relation (unemployment as a cause of poverty). On the other hand $a^{\prime}-$ the income effect of poverty on unemployment - may be positive, as income deprivation may reduce the efficiency of job search, or negative, as it may raise the probability of accepting a job, through the decline of the reservation wage. Psycho-social effects due to poverty (arrow a'), taking place as time in poverty grows longer, are positive (poverty as a cause of future poverty).

Thus, the net effect of past poverty on current poverty is theoretically undetermined. Nevertheless, the body of theoretical and empirical literature on persistence of poverty does highlight that a major concern for social scientists is that past poverty may cause more future poverty (Stevens, 1999; Devicienti, 2002; Giraldo at al, 2003), implying that all relations entering equation (2) could represent altogether a vicious circle $^{15}$.

Poverty and welfare histories have been generated for 5000 hypothetical individuals, for 3650 time units (we may think of this as daily data, recorded for 10 years). Such a large number of time units generates nearly continuous duration data.

Equation (2) is specified as: 


$$
\operatorname{Pr}\left\{P_{t}=1 \mid P_{\text {past }}\right\}=\frac{1}{1+e^{-\left(\gamma_{0}+\gamma_{1} P_{t-1}+\gamma_{2} \sqrt{D u r_{t-1}(P)}\right)}}
$$

where $\operatorname{Dur}_{t}(P)$ represents the amount of time elapsed in poverty within the present spell at time t. We take $\gamma_{1} \neq 0$. Thus, if $\gamma_{2} \neq 0, P_{t}$ depends only on previous state $P_{t-1}$, otherwise $P_{t}$ depends on elapsed duration in poverty at time $t-1$. Equation (3) is set as follows:

$$
\begin{aligned}
& \operatorname{Pr}\left\{A_{t}=1 \mid P_{t}=0\right\}=0 \\
& \operatorname{Pr}\left\{A_{t}=1 \mid P_{t}=1, P_{\text {past }}\right\}=\frac{1}{1+e^{-\left(\delta_{0}+\delta_{1} \sqrt{D r_{t}(P)}\right)}}
\end{aligned}
$$

Under this specification, all welfare recipients are poor. If $\delta_{1}$ is set to zero, probability of welfare participation depends on present poverty status; if $\delta_{1} \neq 0$ it depends on elapsed time in poverty. Four different specific process models have been employed:

model 1: $\gamma_{2}=0, \delta_{1}=0$

model 2: $\gamma_{2} \neq 0, \delta_{1}=0$

model 3: $\gamma_{2}=0, \delta_{1} \neq 0$

model $4: \gamma_{2} \neq 0, \delta_{1} \neq 0$.

Given the aim of the simulation study, we wish to obtain a relevant number of welfare spells: thus, parameters have been set in such a way that most individuals eventually receive social assistance benefit. Parameters are non-negative: past poverty reinforces future poverty. More specifically ${ }^{16}$, in equation (2): $\gamma_{0}=6.65$ and $\gamma_{1}=0.16$ for all models; $\gamma_{2}=0$ in models 1 and 3 and $\gamma_{2}=0.025$ in models 2 and 4 (for example, if a person is poor one day, probability of being steadily poor for at least one year is approximately $67 \%$ in models 1 and 3, and $75 \%$ in models 2 and 4). In equation (3), $\delta_{0}=6.8$ for all models, while $\delta_{1}=0$ in models 1 and 2 and $\delta_{1}=0.025$ in models 3 and 4 (this implies, for example, that in model 1, a person who becomes poor will have a $45 \%$ probability of experiencing at least one year in welfare thereafter). 
After generation of poverty and welfare spells data regarding poverty were discarded. The hazard function:

$$
h(t)=\lim _{d t \rightarrow 0} \frac{P(t \leq T<t+d t \mid T \geq t)}{d t}
$$

for first welfare spells was estimated with the non-parametric method of Kaplan-Meier. $T$ is welfare spell length. A graphical representation of the estimated integrated hazard:

$$
-\ln \hat{S}(t)=\int_{0}^{t} \hat{h}(u) d u
$$

was obtained for each of the four data sets generated from the models described in table 2. If exit rates do not depend on time - i.e. durations follow an exponential distribution - the function should be close to a straight line.

\section{Results}

The estimated integrated hazard is nearly a straight line only for model 1 (fig. 3). We observe a departure from the linear function for models 2 and 3, while model 4 definitely exhibits a concave shape. Notice that a concave functional form for $-\ln S(t)$ implies a decreasing hazard function, i.e., negative duration dependence in the exit rate.

(figure 3 here)

More formally, we also employ different non-parametrical tests (Kolmogorov-Smirnov, Anderson-Darling, Cramer-Von-Mises ${ }^{17}$ ) for the null hypothesis that spell durations follow an exponential distribution. The percentage of times the null hypothesis is rejected at given significance levels has been calculated for each model. If the distribution of spell duration is indeed exponential, this percentage should be close to the corresponding significance value. On the contrary, if the percentage appears to be much higher than the significance value, there is 
strong empirical evidence of the existence of duration dependence. Results are summarised in table 1, and refer to 100 replications for each case. The percentage of rejections is close to significance levels only in model 1 . When current poverty or welfare use are assumed to depend on elapsed duration in poverty, it rises steeply, almost reaching $100 \%$ in model 4 , where both equations of the model comprise duration effects.

(table 1 here)

\section{Conclusive remarks}

(i) The analytical strategy based on the shape of the welfare hazard function is frequently employed to test the subsistence of corruptive effects of welfare benefits that tend to cumulate with time (psycho-social effects, relation $d$, fig 1). As we have shown, negative duration dependence in the exit rate from welfare does not imply the existence of such effects, nor does it imply the existence of any causal effect of being on welfare on working condition. Exit rates from welfare may in fact exhibit negative duration dependence even when welfare cannot possibly affect individual behaviour and choices - and in a perfectly homogeneous environment. We conclude that assessment of the existence of corruptive effects of welfare benefits should not be based on the shape of the hazard function, even when heterogeneity is taken under control. These effects are generally not identifiable with data on welfare spells only. We will discuss alternative strategies in the next section.

(ii) As we have just stated, the problem - a problem of identification - is not related to the classical unobserved heterogeneity v.s. true dependence issue. Let's reconsider this assessment. Consider a homogeneous population at time $t=1$, and a process in and out of poverty, governed by the same rules for all individuals. Because of random luck (or bad luck), the population will become heterogeneous as time goes by. A person who becomes poor at the beginning might experience a higher probability of being poor in the future compared to a more fortunate person who has not fallen into poverty yet. Thus, even if heterogeneity is 
not present at the onset of the process, it will show up with time, being represented by individual's past poverty and unemployment history. If longitudinal data on income and work are available, 'cross-career effects' among the domains of welfare, poverty and unemployment could be investigated. But when data come from administrative archives of social assistance, only welfare spells are available. The additional source of heterogeneity is not observable in this case.

Would the techniques conventionally adopted to control unobserved heterogeneity solve the problem in this context? Probably not. Standard techniques involve the introduction of a time-invariant random component representing neglected heterogeneity, thus, are extremely useful for dealing with unobserved characteristics that do not change or change little in time. On the other hand, the heterogeneity we are dealing with here is intrinsically time-varying: providing a reasonable ad hoc specification for such a time-varying random component seems to be quite a difficult task.

\section{Comparing unemployment exit rates}

The shape of the exit rate from welfare, describing the relation between past and future social assistance participation, represents a very indirect causal link, given by the net effect of all the arrows connecting unemployment, poverty and social assistance (fig. 1). Moreover, as the simulation exercise demonstrates, negative duration dependence can have alternative explanations, not always congruent with the welfare dependence perspective.

Let's go back to the general model previously discussed. Welfare benefits can have a negative effect on recipients' behaviour through: (i) an indirect income effect ${ }^{18}$, causing work effort to decline (arrow $\left.b^{\prime}+a^{\prime}\right)$; (ii) a direct effect - growing with time on welfare - on the probability to exit unemployment, due to cultural and psycho-social factors (arrow d). Both these effects deal with the way social assistance influences the domain of work/unemployment. In this light, any 
assessment of the effects of welfare should focus directly on the relation between benefit receipt and labor market behaviour, in line with the tradition in the literature on work disincentives.

The relevant conceptual framework for the evaluation of welfare dependence is that of the impact evaluation literature (Heckman et al, 1999), according to which the causal effect of a program should be evaluated with counterfactual reasoning. If the aim is the evaluation of the impact on the treated', i.e. how program participation affects recipient's behaviour ${ }^{19}$, an outcome measure of the impact for recipients should be contrasted with that of an appropriate comparison group ${ }^{20}$. In principle, the evaluation design could be based on the comparison between assisted poor vs. unassisted poor $^{21}-$ in order to assess the impact of a specific intervention with respect to the situation where no program is at work - or between assisted poor in different welfare programs, for example programs that allocate different amounts of benefit ${ }^{22}$. Techniques for controlling unobserved heterogeneity are also relevant in this context.

In this framework, let's try a simple line of reasoning. Assume that we can find a group of non-recipient poor who are not too different from recipients, and that these differences can be taken under control. We could compare the exit rates from unemployment for the two groups, the relevant question being: does benefit receipt reduce this exit rate? (Contini and Melis, 2002; Terracol, 2004) ${ }^{23}$. Evidence of welfare dependence is provided if, ceteris paribus, non-recipients leave unemployment more rapidly than recipients, i.e. the exit rate for non-recipients is higher than that of recipients. Notice that welfare dependence is not related to the shape of the exit rate from unemployment, thus it does not imply negative duration dependence ${ }^{24}$.

If heterogeneity is properly taken into account, this strategy does allow for correct inference on welfare dependence. We question whether the following issue can be addressed as well: to what extent is welfare dependence due to income effects or to psycho-social effects?

We have argued that psycho-social effects develop with time elapsed on welfare, while income effects are not time-dependent. Thus, identification of the former could be attained by comparing unemployment exit rates of long and short-term assisted (including currently elapsed 
time on welfare as a time-varying covariate). Evidence of psycho-social effects is provided if work effort decays with time on welfare. But, once again, a significant coefficient for elapsed time on welfare does not prove the existence of detrimental effects of the benefit. As time spent in welfare can also stand for time in poverty, separating the psycho-social effect due to time in welfare (type $d$ effects) from that due to time in poverty (type $a^{\prime \prime}$ ) can be difficult ${ }^{25}$.

If data on poverty spells are also available, a time-varying covariate representing the relevant features of individual's past poverty history could be added to the model. But this requires: first, that poverty and welfare spells are not nearly overlapping, and this is not usually the case in universalistic welfare systems. Second, that elapsed time in poverty and elapsed time on welfare are additive effects, which seems to be quite a strong assumption.

We conclude that 'dissecting' the effects underlying welfare participation is extremely important in order to identify - from a theoretical point of view - the different mechanisms at work: on one hand, distinguishing negative effects of the benefit from those related to conditions different from that of being a welfare recipient; on the other hand, distinguishing the different modes of welfare dependence. Nevertheless, the above discussion highlights that the empirical assessment of the different mechanisms has no simple general solution: very rich data archives are required and evaluation designs must be strictly related to institutional and cultural factors, thus, have to be deeply rooted into the local environment.

\section{Notes}

1. It is well known from the econometric literature that negative duration dependence may be a spurious effect due to unobserved heterogeneity. The point we want to make is that factors other than that of unobserved heterogeneity make identification of the effects of welfare a difficult task when the empirical analysis is based on the shape of exit rate from welfare.

2. Since many recipients experience more than one spell, some studies focus on total time on welfare in a given time interval, or on the fraction of total income that derives from welfare over a fixed time period (Moffit, 1992; Gottschalk and Moffit, 1994).

3. Aid to Families with Dependent Children, the main income support for the poor in the USA, specifically designed to support lone mothers with children. The program was replaced in 1996 by the more restrictive program Temporary Aid for Needy Families.

4. Differences among states in the potential maximum benefit level under the AFDC program were very marked; moreover this level underwent significant changes in the 1960s to '80s period (Moffit, 1992). 
5. Let $T$ be the duration of the welfare spell. The hazard function (also called 'exit rate') describes the instantaneous exit probability given survival to time $t$ and is given by $h(t)=\lim _{d t \rightarrow 0} \frac{P(t \leq T<t+d t \mid T \geq t)}{d t}$.

6. Evidence supporting the existence of negative duration dependence is not compelling: in a few studies such dependence does not appear to be statistically significant (Blank, 1989; Fitzgerald, 1991; Walker and Shaw, 1998, see also Bane and Elwood, 1994).

7. We consider a group of people, heterogeneous with respect to the level of 'ability' and identical for everything else, receiving subsidies in the same period. Let's observe the exit rate from assistance. The original group includes able and less able: the rhythm of exit from assistance is relatively fast at first. As time passes, the group of beneficiaries grows smaller, the more able having found work. Hence only less able individuals are left. Even in the absence of corruptive effects of assistance on beneficiaries' behaviour, we observe an exit rate decreasing over time.

8. Some authors (Sandefur and Cook, 1998; Dahl and Lorentzen, 2003) introduce a random component in order to take into account unobserved heterogeneity.

9. Moffit on the other hand claims that this approach is not well supported by economic theory.

10. As long as eligibility conditions are still met. Empirical research shows that exits from $A F D C$ are often due to marriage or to the fact that women no longer have eligible children (Bane, Elwood; 1994).

11. There is an extensive econometric literature addressing the problem of the existence of true negative duration dependence in the exit rate from unemployment, i.e. the possibility that the longer people stay out of the labor market, the more difficult re-entry would be.

12. The income effect may instead be stronger for mothers, as the cost of child care will constitute and additional 'tax' on labor supply.

13. Arrow $d$ can also represent a positive effect of the subsidy on work, in cases where financial benefits are integrated with activation measures aimed at reinsertion in the labor market.

14. In Bane and Ellwood (1994) the term 'psycho-social' refers to the 'expectancy' model only. Here the label includes the effects of the 'cultural' model as well.

15. We are aware that this concern is sometimes related to the potential negative effect of welfare on poverty (the 'welfare trap', which in this restricted version of the model cannot take place). Nevertheless persistence of poverty may also occur for psychological and cultural reasons not related to the benefit.

16. Similar results are obtained with different values of the parameters (with the same sign). Other parameter configurations are not shown: purpose of the simulation study is merely to provide a counterexample to the general 'theory' that negative duration dependence should imply welfare dependence.

17. Given the length of the observation window, only very few right censored first spells are found.

18. A positive effect may be at work as well, if the subsidy has empowerment effects (supporting the costs of jobsearch and alleviating negative psycho-social effects of income deprivation).

19. Some studies focus instead on the global impact of the program, which also involves 'entry effects' (non-eligible changing behaviour in order to become eligible) and substitution effects.

20. The counterfactual is represented by the (average) outcome which would have occurred to the 'treated' if they had not been treated. Under certain (often untenable) assumptions, the counterfactual can be consistently estimated by the (average) outcome of a convenient comparison group, or by that of the treatment group before implementation of the program. The former strategy implies the existence of a proper comparison group (i.e. the absence of selection bias on unobservables); the latter, the possibility of keeping control over the ongoing changes in the environment.

21. The strategy is difficult to pursue in systems with universalistic orientation (Saraceno, 2002) where it is rare to find non-assisted poor. Recipients and non-recipients have intrinsic differences in 'category-based' assistance regimes, where eligibility rules refer not only to the economic condition, but also to other circumstances (for example, the household's composition): this occurs in US programs AFDC and TANF, but also in Italy and Germany (Bonny, Bosco; 2002). In all cases, if recipients and non-recipients differ with respect to unobservable characteristics, the problem of 'selection bias' has to be dealt with.

22. Most of the studies on welfare dependence do not strictly refer to the impact evaluation framework. One exception is Fortin et al (2004), which exploits an exogenous change occurred in the Canadian Quebec-Welfare Program, thus considered a 'natural experiment'.

23. A ceteris paribus reasoning is not easy. Contini and Melis (2002) - referring to the Italian assistance regime where norms regulating access to benefits leave social workers a wide margin of discretionality and the transfer is not always 'according to need' - compare the behaviour of recipients when receiving the benefit with that of the same recipients at times when they are not assisted. Terracol (2004) evaluating the French universalistic policy Revenu Minimum d'Insertion (RMI) program, employ as a comparison group the eligible non-recipients, as not all the eligible claim the benefit. In order to deal with the endogenous nature of participation given eligibility, the author jointly estimates the equation for the exit rate from unemployment spell and the equation explaining take-up behaviour by eligible agents.

24. This effect may instead be represented by arrow $c$ in fig.1.

25. Policy implications are quite different in the two cases. 


\section{Acknowledgements}

We are grateful to ...

Financial support from the Italian Ministry of Education, University and Research for the PRIN project (2005): "La valutazione dell'impatto degli interventi pubblici: metodi e studi di caso".

\section{References}

Bane M., Elwood D. (1994). Welfare Realities: From Rhetoric to Reform, Cambridge, MA, Harvard University Press.

Blank R. (1989). Analyzing the Length of Welfare Spells, Journal of Public Economics, 39, 245-274.

Blank R. M. (2002). Evaluating Welfare Reform in the United States, Journal of Economic Literature, XL, 1105-1166.

Bonny Y. Bosco N. (2002). Income support measures for the poor in European cities, Saraceno (eds), Social Assistance Dynamics in Europe: National and Local Poverty Regimes, The Policy Press, Bristol, 81-125.

Bosco N., Contini D., Negri N. (1999). Out of welfare: functioning of income support in Torino, Quality and Quantity, 33, 243-260.

Buhr P., Weber A. (1998). Social assistance and social change in Germany, in Leisering L. e Walker R. (eds), The dynamics of modern society: Poverty, policy and welfare, Bristol, The Policy Press, 183-198.

Chay K. Y., Hoynes H., Hyslop D. (2005). A non-experimental analysis of true state dependence in monthly welfare participation sequences, Journal of Econometrics, forthcoming

Contini D., Melis N. (2002). I sussidi assistenziali inducono dipendenza? Evidenze dall'archivio sui residenti in edilizia pubblica, Statistica Applicata, 12, 197-225.

Dahl E., Lorentzen T. (2003). Explaining exit to work among social assistance recipients in Norway: heterogeneity or time dependency?, European Sociological Review, 19, 5, 519-536.

Dazinger S., Haveman R., Plotnick R. (1981). How income transfers affect work, savings and the income distribution, Journal of Economic Literature, 19, 3, 975-1028.

Devicienti F. (2001). Poverty persistence in Britain: a multivariate analysis using the BHPS, 19911997, Journal of Economics, Suppl. 9, 1-34.

Ermish J. F., Wright R. E. (1991). Welfare benefits and lone parents' employment in Great Britain, The Journal of Human Resources, 424-456. 
Fitzgerald J. (1991). Welfare durations and the marriage markets. Evidence from the Survey of Income and Program Participation, The Journal of Human Resources, 545-561.

Fortin B., Lacroix G., Drolet S. (2004). Welfare benefits and the duration of welfare spells: evidence from a natural experiment in Canada, Journal of Public Economics, 88, 1495-1520.

Gangl M. (2003). Tra sussidio sociale e mercato del lavoro: un'analisi empirica nella Repubblica Federale Tedesca, in Alcock P. e Siza R. (eds), La Povertà Oscillante, Sociologia e Politiche Sociali, 6, 2, 147-167.

Giraldo A., Rettore E. , Trivellato U. (2001). The persistence of poverty: true state dependence or unobserved heterogeneity? Some evidence form the Italian survey on household income and wealth", Working Paper n. 40, Progetto COFIN 1999 "Occupazione e disoccupazione in Italia: misura e analisi dei comportamenti".

Gottschalk P. e Moffit R. (1994). Welfare Dependence: Concepts, Measures, and Trends”, American Economic Review, 84, 2, 38-42.

Granovetter M. (1995). Getting a Job: A Study of Contacts and Careers. University of Chicago Press, Chicago, $2^{\text {nd }}$ edition.

Gustaffson B., Muller R., Negri N. and Voges W. (2002). Paths through (and out) social assistance, in Saraceno C. (eds), Social Assistance Dynamics in Europe: National and Local Poverty Regimes, The Policy Press, Bristol, 173-234.

Heckman, J., LaLonde, R. and Smith, J. (1999) "The Economics and Econometrics of Active Labor Market Programs", Handbook of Labor Economics, 3A, 1865-2097, North-Holland

Hedström P. (2005). Dissecting the Social: on the Principles of Analytical Sociology, Oxford University Press.

Hoynes H., MaCurdy T. (1994). Has the Decline in Benefits Shortened Welfare Spells?, American Economic Review, 84, 2, 43-48.

Lancaster T. (1990). The Econometric Analysis of Transition Data, Cambridge University Press, Cambridge.

Leisering L., Leibfried S. (1999). Time and Poverty in Western Welfare States, Cambridge University Press, Cambridge.

Leisering L., Walker R. (1998). Making the future: from dynamics to policy agenda, in Leisering L. e Walker R. (eds) (1998). The dynamics of modern society: Poverty, policy and welfare, The Policy Press, Bristol, 265-285.

Leisering L., Walker R. (eds) (1998). The dynamics of modern society: Poverty, policy and welfare, The Policy Press, Bristol.

Moffit R. (1992). Incentive Effects of the U.S. Welfare System: a Review, Journal of Economic Literature, 30, 1-61. 
Moffit R. (2002). The Temporary Assistance for Needy Families Program, NBER Working Paper $N^{\circ} 8749$.

Moffit R. (2003). The role of non-financial factors in exit and entry in the TANF program, The Journal of Human Resources, XXXVIII Supplement, 1221-1254

Negri N., Saraceno C. (1996). Le politiche contro la povertà in Italia, il Mulino, Bologna.

O’Neill J.A., Bassi L.J., Wolf D.A. (1987). The duration of welfare spells, The Review of Economics and Statistics, 241-248.

Sandefur G. D., Cook S. T. (1998). Permanent Exits from Public Assistance: the Impact of Duration, Family and Work, Social Forces, 77, 2, 763-787.

Saraceno C. (eds.) (2002). Social Assistance Dynamics in Europe: National and Local Poverty Regimes, The Policy Press, Bristol.

Shaw A., Walker R. (1996). Disjointed interaction: the labour market and the benefit system, in Meadows P. (eds), Work out or work in?, York Publishing Service/Joseph Rowentree Foundation, York, 87-115.

Stevens A. H. (1999). Climbing out of poverty, falling back in: measuring the persistence of poverty over multiple spells, Journal of Human Resources, 34, 3, 557-588.

Terracol A. (2004). Welfare programs and unemployment duration in France, unpublished preliminary version

Van der Berg G. J., Van der Klaauw B., Van Ours J.C. (2004). Punitive sanctions and the transition rate from welfare to work, Journal of Labor Economics, 22, 1, 211-241.

Walker R., Ashworth K. (1998). Welfare benefits and recession in Great Britain, in Leisering L. e Walker R. (eds) (1998), The dynamics of modern society: Poverty, policy and welfare, The Policy Press, Bristol, 199-220.

Walker R., Leisering L. (1998). New tools: towards a dynamic science of modern society, in Leisering L. e Walker R. (eds) (1998), The dynamics of modern society: Poverty, policy and welfare, The Policy Press, Bristol, 17-33.

Walker R. e Shaw A. (1998). Escaping from social assistance in Great Britain, in Leisering L. e Walkr R. (eds) (1998), The dynamics of modern society: Poverty, policy and welfare, The Policy Press, Bristol, 183-198. 


\section{Authors' Addresses}

Dalit Contini, Università di Torino, Dipartimento di Statistica e Matematica Applicata, Piazza Arbarello, 8, 10122 Torino, dalit.contini@,unito.it

Nicola Negri, Università di Torino, Dipartimento di Scienze Sociali, Via S. Ottavio 50, 10124

Torino, nicola.negri@unito.it 